\title{
Determinantes dos preços de ingressos de futebol do campeonato brasileiro, 2012 a 2018
}

\section{Determinants of soccer tickets prices of the Brazilian championship, 2012-2018}

\author{
Graciela Aparecida Profeta* \\ Ivens Nunes Thomaz* \\ Patrícia de Melo Abrita Bastos* \\ Vladimir FARIA dos SANTOs*
}

\begin{abstract}
This article is aimed to measure the relationship between the determinants of football tickets prices for the Brazilian Championship from 2012 to 2018. The literature was used to identify determinants and the theory of full-cost pricing by Hall and Hitch was adopted. Panel data models were applied to estimate the relationships between the determinants and football tickets prices. The results showed that most determinants explained prices. Therefore, Hall and Hitch's full-cost pricing theory and the empirical model explained prices formation for football tickets in Brazil.
\end{abstract}

Keywords: sport economics, demand, Brazilian championship, panel data.

\section{Resumo}

Neste artigo objetivou mensurar as relaçóes entre os determinantes dos preços dos ingressos de futebol para o Campeonato Brasileiro, de 2012 a 2018. Utilizouse a literatura para identificar determinantes e adotou-se a teoria do custo total formulada por Hall e Hitch. Para a estimação das relaçóes entre os determinantes e os preços dos ingressos de futebol aplicou-se modelos de dados em painel. Os resultados apontaram que a maioria dos determinantes explicavam os preços. Logo, a teoria do custo total de Hall e Hitch e o modelo empírico explicaram a formaçáo de preços para os ingressos de futebol no Brasil.

Palavras-chave: economia do esporte, demanda, campeonato Brasileiro, dados em painel.

*Universidade Federal Fluminense, correos-e: graciela_profeta@yahoo.com.br, ivensnt@gmail. com,patriciaabrita@gmail.com y vladi_fs@yahoo.com.br 


\section{Introduçáo}

Desde o anúncio de que a Copa do Mundo FIFA (Federação Internacional de Futebol) de 2014 seria sediada no Brasil, os estádios das cidades-sede precisaram passar por reformas profundas em sua estrutura, incluindo demoliçóes parciais ou completas, além da construção de instalaçóes totalmente novas nas capitais Manaus, Cuiabá, Natal, Recife e São Paulo, atendendo às exigências e requisitos da FIFA, entidade responsável pela organização do evento e custando valores bilionários ao erário público e à iniciativa privada.

Estádios públicos e históricos, como o de nome do Jornalista Mário Filho, popularmente conhecido como Maracanã, construído para a Copa do Mundo de Futebol FIFA de 1950, tendo se tornado obsoleto com o passar dos anos, necessitou ser reformado e modernizado diversas vezes. Porém, nenhuma mudança anterior foi tão significativa e radical quanto a que ocorrera para a Copa do Mundo FIFA de 2014, alterando-se completamente a configuração interna do estádio e reduzindo a capacidade total em busca de maior conforto e aumentando, em contrapartida, o número de camarotes e espaços para outros eventos, além da construção de um shopping na área externa.

As mudanças promovidas para o evento internacional impactaram a forma como os torcedores dos clubes nacionais, na qual utilizariam os estádios posteriormente ao evento, frequentariam os mesmos e se comportariam. As arquibancadas foram substituídas por assentos mais confortáveis e espaçosos, foram construídos camarotes, restaurantes e lojas. A mudança estrutural dos estádios, contudo, provocou um aumento nos custos operacionais, que outrora sob administração pública, agora se encontravam sob a administração de consórcios formados por empresas privadas ou das construtoras que implementaram as reformas, com as quais os lucros dos jogos eram divididos.

Este processo foi observado por Holzmeister Oswaldo Cruz (2005) e Alvito (2006), e os autores concordam que os torcedores são cada vez mais tratados como consumidores e o ambiente dos estádios não tem mais como prioridade proporcionar o sucesso esportivo dos clubes por meio do incentivo da participação dos torcedores na ida aos estádios a fim de gerar receita, mas criar um ambiente de negócios com o intuito de atrair patrocinadores, fomentar programas de sócio torcedor, venda de produtos licenciados, além de visitação a restaurantes, bares e museus. Além disso, tragédias devido a conflitos entre torcidas organizadas e a superlotação dos estádios, pressionaram a adoção de medidas de segurança nos estádios, como a colocaçáo de cadeiras, que substituiu a tradicional arquibancada de cimento e com isso gerou redução da capacidade de lotação dos estádios. 
Todas essas alterações implicaram em mudanças no público frequentador dos estádios e aumento nos preços dos ingressos, o que gerou discussão e questionamentos por parte da imprensa e dos próprios torcedores sobre a exclusão das camadas mais populares que outrora frequentavam os estádios, um processo que é visto como elitização do público assíduo dos estádios. Holzmeister Oswaldo Cruz (2005) aponta que os fatores que provocaram este aumento nos preços dos ingressos foram justamente as mudanças estruturais promovidas para uma melhor segurança, o que certamente têm impacto nos custos operacionais dos estádios, e fatores estritamente econômicos.

Todavia, há de se ressaltar o papel dos ídolos tanto na captura do torcedor quanto nas suas decisóes de alocação de sua renda em compras de produtos de futebol, tal como ingressos. Neste sentido, tem-se como exemplo o trabalho de Simóes (2017), que analisou aspectos relacionados aos ídolos do futebol na atualidade considerando três eixos: $i$ ) habilidades técnicas como jogador em campo; ii) qualidades e valores de um sujeito na vida; iii) visibilidade e estratégias de marketing. Simões (2017) aponta que o futebol busca a atençáo de tantos torcedores a partir do fascínio que desperta, por ser um fenômeno que atrai constantemente a atenção. Além das habilidades atléticas que leva ao fascínio do torcedor pelo seu ídolo, tem-se também o carisma do mesmo que pode ser visto justamente como qualidades e valores que são destacados na trajetória de um jogador e que participam da construçáo de sua empatia com o público.

Também, tem-se a estratégia de marketing aplicada à construção do ídolo. Neste caso, dado um mundo em que os meios de comunicação de massa são predominantes, estar visível, sempre presente, é um elemento configurador dos ídolos. E, é esse tipo de combinação de estratégias que os clubes consideram quando contratam ou criam seus ídolos, no intuito de capturar e fidelizar seus torcedores e torna-los consumidores de produtos. Logo, o papel dos ídolos acaba também sendo um determinante do preço do ingresso, mas que na presente pesquisa, optou-se por não inserir esse determinante no modelo empírico dado o horizonte temporal e às dificuldades de se avaliar objetivamente quais e quantos ídolos os clubes tiveram nos anos analisados.

Além disso, faz-se necessário ressaltar outro determinante que pode afetar não só dos preços dos ingressos, mas de todos os produtos e serviços relacionados ao futebol, que é a natureza do ser humano. Segundo Rial Butier e Lebrini, o "torcedor de futebol parece de certa forma um ser humano diferente. A paixão e o envolvimento emocional com seu time de coração colocam em dúvida a racionalidade do processo decisório de compra" (2013: 147). 
Ainda em relação ao comportamento do torcedor de futebol e a decisão em adquirir um produto (ou pacote) desse mercado, Sampaio et al. (2015) discutem em eu estudo a questão do envolvimento e do orgulho nas decisóes dos torcedores de futebol. Para Sampaio et al., "os torcedores orgulhosos de seu time seriam mais propensos a se comprometer com a equipe e a atingir níveis de lealdade mais altos (...) Isso implica um comparecimento regular aos jogos e um envolvimento afetivo duradouro" (2015: 115).

Assim, pode-se dizer que as características do torcedor enquanto ser humano apaixonado pelo futebol o tornam irracional sob o ponto de vista econômico em relação à sua decisão de alocação de sua renda. Isto implica em afirmar que fatores como renda e desempenho do clube, que são mensuráveis, não necessariamente explicam totalmente o comportamento dos preços, que teriam, portanto, influência do comportamento humano, mas este é de difícil mensuração. Então, na presente pesquisa, o comportamento humano não foi inserido como um determinante dos preços dos ingressos de futebol pela complexidade de mensura-lo, o que poderia gerar um viés de especificação do modelo e inconsistência nos resultados obtidos.

Feitas tais consideraçóes, o objetivo que norteou este artigo foi discutir o processo de elitização do futebol e identificar e mensurar os impactos dos determinantes dos preços dos ingressos das partidas de futebol do Campeonato Brasileiro de Futebol da Série A no período de 2012 a 2018. Para tanto, utilizou-se de uma revisão de literatura com vistas a levantar variáveis que pudessem determinar o preço dos ingressos de futebol do campeonato brasileiro da série $\mathrm{A}$, além de elaborar e estimar um modelo econométrico para mensurar as relaçóes entre tais determinantes e os preços.

\section{Revisão de Literatura}

\subsection{A profissionalizaçáo do futebol no Brasil a partir da década de 1920 e as mudanças no papel do estádio na perspectiva de Holzmeister Oswaldo Cruz}

A construção do estádio São Januário e a inclusão de negros e pobres nos times de futebol do Clube de Regatas Vasco da Gama durante a década de 1920 propiciaram a popularização do esporte no Brasil, sendo possível obter-se rendas maiores e pagar salários fixos aos atletas, cujo o único critério de recrutamento pelo qual eram submetidos era o de habilidades na prática do futebol. Embora tenha sofrido resistência dos clubes já 
estabelecidos, o processo de profissionalização foi adotado pelos demais clubes da cidade do Rio de Janeiro.

De maneira arcaica se estabelecia, portanto, o início do processo simultâneo de profissionalização e popularização do futebol brasileiro que posteriormente foi seguido pelos demais clubes, até que na década seguinte, o governo federal estabeleceu, pelo decreto-lei n ${ }^{\circ} 3.199$ de 14 de abril de 1941, a criação do Conselho Nacional de Desportos (CND) e toda regulamentação do esporte nacional. Havia, portanto, um interesse do Governo de Getúlio Vargas na utilização do futebol como um instrumento de integração nacional e sustentação do regime Varguista (Holzmeister Oswaldo Cruz, 2005).

É possível verificar ainda que a construção do estádio do Maracanã, devido aos seus setores que comportavam diversas camadas sociais distintas, "protagonizou o processo de coletivização da torcida [...] dando-lhe uma identidade nacional, que mexe com as emoções da população [...]" (Holzmeister Oswaldo Cruz, 2005: 75).

Após a Copa do Mundo de 1950, no entanto, o estádio se tornou o principal palco dos jogos dos clubes de futebol carioca, sendo o setor da arquibancada o mais atrativo às camadas populares e responsável pela posterior formação, na década de 1960, das torcidas organizadas. Posteriormente, o Maracanã passou por mudanças estruturais, como o fim, ou restriçãao, da popular Geral e da colocação de assentos e setorização das arquibancadas do anel superior, onde tradicionalmente se acomodam as torcidas organizadas, antes mesmo da Copa do Mundo FIFA disputada em 2014.

Também se notou que o Maracanã, a Arena da Baixada e o Estádio Caio Martins passaram por um processo semelhante ao ocorrido nos estádios ingleses. Sofreram reformas e mudanças para que se atendesse não só às medidas de segurança, mas também por razões econômicas, pois "como vimos, estáo transformando o jogo, convertendo-o em um espetáculo, em um produto a ser comercializado e que pressupóe uma platéia composta por consumidores em detrimento dos torcedores" (Holzmeister Oswaldo Cruz, 2005: 95).

No Brasil, estas mudanças tiveram início a partir da década de 1990 com a aprovação das leis Pelé e Zico com intuito de promover a modernização do futebol Brasileiro, que apenas no fim da década de 1990, por meio de uma maior cobrança das instituiçóes públicas, da imprensa e de grupos de torcedores, criou-se o Estatuto do Torcedor, no ano de 2002.

Em 2000, o Maracaná passou por reformas onde foram criados diversos setores com objetivo de atender à demanda de públicos específicos e preços diferenciados em cada setor. Com o setor central do anel superior, o branco, sendo direcionado a turistas e torcedores de ambos os times (em 
caso de clássicos cariocas, ou seja, confrontos entre Flamengo, Fluminense, Botafogo e Vasco) dos quais, geralmente estavam acompanhados da família ou temiam a proximidade para com as torcidas organizadas.

\subsection{O processo de transformaçáo de torcedores em consumidores}

A Revolução Industrial e o ritmo fabril foram aspectos decisivos na criação de novas formas de diversão e a segunda revolução industrial, ao fim do século XIX, possibilitou a amplificação deste processo e expansão dos mesmos pelo mundo todo. Isso se deu por meio da melhora e avanço dos meios de comunicação, o que culminou em veículos de informação cada vez mais massivos, como a televisão (Andrade de Melo, 2010). Assim, a partir da década de 1970, a Copa do mundo de futebol masculino pôde ser transmitida para milhóes de pessoas em vários países, tornando-se uma ferramenta de marketing e inserindo o futebol no sistema capitalista de mercado.

A criação de um campo esportivo planetário onde estão presentes mídias especializadas, multinacionais no papel de anunciantes e/ou na produção direta de produtos esportivos a serem mundialmente consumidos, tornou o esporte um espetáculo midiático e uma oportunidade lucrativa, portanto, de investimento; e que transformou o torcedor comum em um potencial consumidor. Por exemplo, tem-se os Estados Unidos como o precursor do esporte-espetáculo, tendo esta indústria um destaque importante na economia Norte-Americana (Alvito, 2006).

Alvito (2006) também destaca a importância que o esporte-espetáculo tem para o capitalismo contemporâneo, na qual a lógica se baseia na cultura e na produção artificial de necessidades. Sem a transformação do supérfluo em produtos de primeira necessidade, o capitalismo enfrentaria uma crise de superprodução, sendo necessário, portanto, que se recorra a irracionalidade e à emoção, principalmente numa sociedade que exige cada vez mais controle emocional.

Logo, o futebol se tornou carro-chefe da indústria do entretenimento, servindo de espaço publicitário em diversas mídias por se tornar o esporte mais popular do mundo. Além disso, com valores de patrocínios cada vez mais vultuosos, é comum que a imprensa esportiva dedique cada vez mais espaço para tratar especificamente do assunto (Alvito, 2006).

Neste sentido, ainda segundo Alvito (2006), os torcedores são cada vez mais considerados como consumidores pelas entidades esportivas e comerciais ligadas ao esporte, tais quais a televisão e anunciantes (patrocinadores); com isso, observa-se um esforço por parte dos clubes e seus patrocinadores em garantir que o espetáculo seja visualmente mais agradável, e para isso, utilizam de força policial e de vigilância sob a justificativa de garantir 
segurança ao público; mas, que na verdade, também visa evitar a associação de suas marcas a possíveis atos de desordem.

Náo obstante ao fato de que a questão da segurança seja importante, muitas vezes seu uso excessivo em prol do espetáculo midiático pode promover algum grau de intimidação e cerceamento à liberdade dos torcedores (Alvito, 2006). Por exemplo, tem-se que o processo de transformação dos torcedores em consumidores passa muito pelo combate às torcidas organizadas, que a despeito de promoverem belos espetáculos nas arquibancadas, promovem também violência, sendo, portanto, desinteressantes à televisão e mídia esportiva com um todo, dificultando o uso do futebol como plataforma publicitária.

\subsection{Medidas de segurança, mudança dos estádios e profissionalizaçáo: o caso britânico}

Por todo o século XX os estádios britânicos foram palco de acidentes devido às brigas entre hooligans ${ }^{1}$ e, principalmente, superlotação e más condiçôes estruturais dos estádios, sendo registrados mais de 300 vítimas fatais, além de centenas de feridos. O principal acidente ocorreu em 1989 no estádio Sheffield Hillsborough, numa partida entre Liverpool e Nottingham Forest, onde a superlotação vitimou 100 pessoas imprensadas no alambrado (Holzmeister Oswaldo Cruz, 2005).

Após esta tragédia, foram tomadas medidas para o aumento da segurança nos estádios da Inglaterra baseadas no Relatório de Taylor (Taylor Report), principalmente a proibição de venda e consumo de bebidas alcoólicas no interior dos estádios e modificaçóes dos setores onde os torcedores assistiam ao jogo de pé, também chamados de terraces. ${ }^{2}$ Os impactos destas medidas na cultura e no ambiente dos estádios britânicos foram enormes, afastando os torcedores de camadas mais pobres e operárias que ao mesmo tempo, em geral, são os mais fanáticos e mais apaixonados pelos clubes (Holzmeister Oswaldo Cruz, 2005).

Portanto, as medidas de segurança são apontadas por Holzmeister Oswaldo Cruz (2005) como um dos fatores determinantes para a definição da estrutura dos estádios ingleses, porém não são os únicos. Na verdade, observa-se que esse processo de reestruturação dos estádios está pautado na lógica econômica (Holzmeister Oswaldo Cruz, 2005).

Ademais, a partir da década de 1980, pôde-se notar um aumento na capacidade financeira dos clubes de futebol, principalmente dos britânicos,

\footnotetext{
${ }^{1}$ Indivíduo ou grupo que é violento, arruaceiro e vândalo, principalmente quando presentes em competiçóes esportivas. Torcedor violento.

${ }^{2}$ Setores sem assentos nos quais o torcedor assistia ao jogo em pé. No Brasil estes setores eram conhecidos como Geral ou Gerais.
} 
que foram os primeiros a implementarem uma gestão empresarial de suas finanças. Tal ação, de forma conjunta ao aumento de outras fontes de receitas, como os direitos de transmissão de televisão, foi um fator responsável pela mudança em seus estádios, para além das questôes de segurança (Holzmeister Oswaldo Cruz, 2005).

Com o surgimento no futebol de profissionais responsáveis pela administração das empresas, como diretores especializados em marketing, vendas e financeiro e a posterior mudança nas restriçóes ao uso do uniforme como plataforma publicitária, foi possível a estampa de patrocinadores nos uniformes dos clubes e abriu-se maior espaço e novas oportunidades para geraçáo de receitas para os clubes (Holzmeister Oswaldo Cruz, 2005). Logo, dado esse contexto, Holzmeister Oswaldo Cruz (2005) verificou, assim como Alvito (2006), que o futebol foi inserido num processo de mercantilização da cultura, na forma de lançamentos de produtos e produção em massa e em ritmo industrial, propiciando o surgimento dos pós-torcedores. Um novo tipo de torcedor com maior senso crítico e grande propensão ao consumo destes itens.

Ao fim da década de 1980, portanto, os clubes ingleses geravam mais receitas oriundas dos licenciamentos de produtos relacionados às suas marcas e direitos de transmissão pagos pela televisão do que propriamente da bilheteria de seus jogos. Pode-se observar, portanto, uma mudança do público frequentador dos estádios de futebol na Inglaterra durante esse período, com esse espaço servindo cada vez mais como um atrativo a patrocinadores e para promover açôes de marketing que busquem valorizar as marcas dos clubes e atrair investidores e cada vez menos com o objetivo de receber os torcedores mais fanáticos.

\subsection{Alguns estudos empiricos sobre preço e demanda por jogos de futebol}

García e Rodríguez (2002) e Falter e Perignon (2000) levantaram diversos estudos empíricos acerca da demanda por partidas de futebol, e apontaram um padráo de elementos como imprevisibilidade do resultado da partida, custo de oportunidade e qualidade, ambiente econômico e incentivos monetários e nấo-monetários para ir ao estádio, sendo estes importantes na formação de preços.

Madalozzo e Villar (2009) dividem as variáveis que podem ter impacto sobre a demanda nas categorias: estruturais, de qualidade esperada, de performance e de incerteza acerca do resultado da partida. As variáveis estruturais tratadas pelos autores foram preços dos ingressos, o PIB per capita, a capacidade do estádio, o dia da semana, promoção da Nestlé e o número de jogos como mandante por mês. 
Já, as variáveis da categoria de qualidade esperada da partida são: título nacional ou internacional conquistado no ano anterior pelo time mandante, título nacional ou internacional conquistado no ano anterior pelo time visitante, título estadual conquistado no ano pelo mandante, jogo Clássico, segunda divisão no ano anterior e time visitante dos estados de São Paulo (SP) e Rio de Janeiro (RJ).

No que se refere à categoria performance, utilizaram os pontos conquistados nas últimas três rodadas pelo time mandante, classificaçáo do time mandante e classificaçáo do time visitante. E por fim, na categoria incerteza quanto ao resultado da partida, elencaram a chance de alcançar a liderança, chance de sair da zona de rebaixamento e número da rodada (Madalozzo and Villar, 2009).

Ainda, segundo Madalozzo e Villar (2009: 646), “as variáveis estruturais tiveram o impacto esperado e, com exceção da variável Número de partidas com mando de campo por mês, todas as variáveis são significativas”. Sobre a Promoção Nestlé, o autor enfatiza:

A promoção da Nestlé teve um efeito positivo e muito significativo -o maior do modelo, embora só tenha ocorrido em $8.32 \%$ dos jogos. Esses efeitos tornam algumas interpretaçôes possíveis. Em linhas gerais, percebese que o público potencial é maior do que o que normalmente frequenta os jogos (Madalozzo and Villar, 2009: 645).

Então, nota-se que promoções e diminuições no preço do ingresso causaram um aumento da demanda pelos jogos, assim como clássicos e jogos em que o visitante é um clube do estado do Rio ou Sáo Paulo e o bom desempenho dos clubes mandantes. Por fim, Madalozzo e Villar (2009) concluem que a maioria das variáveis foram estatisticamente significativas e que ao menos uma por categoria teve impacto relevante.

Bruscato Bortoluzzo et al. (2017) estudaram a demanda por partidas de futebol para o período de 2004 a 2013. Foram estimados três modelos distintos: o modelo de mínimos quadrados ordinários, o modelo TOBIT e o modelo GL, modelo de mínimos quadrados generalizado. As variáveis foram divididas em três grupos: ambiente econômico (PIB per capita e a populaçáo da cidade em que se realizara a partida), variáveis para a qualidade do produto e variáveis que buscam mensurar os incentivos monetários e não-monetários (Bruscato Bortoluzzo et al., 2017). Os resultados obtidos para todos os modelos corroboraram a previsão de que quanto maior a população da cidade, maior a demanda por jogos de futebol. Quanto a um maior PIB per capita, há uma diminuição da demanda, concluindo-se, como Madalozzo e Villar (2009), que o futebol é um bem inferior. Ou seja, a elasticidade-renda da demanda é menor que 1 (Bruscato Bortoluzzo et al., 2017). 
As variáveis relativas à qualidade do produto abrangem a qualidade dos times mandantes e dos times visitantes. Além destas, Bruscato Bortoluzzo et al. (2017) acrescentaram mais duas, a quantidade de gols marcados pelos dois times nas últimas três rodadas e variáveis dummy, com o objetivo de mensurar o impacto da importância de cada quarta parte do campeonato. À medida que o campeonato avança, esperava-se, segundo Bruscato Bortoluzzo et al. (2017), que houvesse um aumento da demanda pelos jogos, como foi verificado nos resultados. Os resultados foram significativos para a maioria das variáveis. Assim como os resultados de Madalozzo e Villar (2009), os clássicos e jogos que envolveram clubes dos estados do RJ e SP como visitantes, impactaram positivamente na demanda.

Para o grupo de variáveis de incentivos monetários e não-monetários, as utilizadas por Bruscato Bortoluzzo et al. (2017) foram: o preço dos ingressos em média; jogo realizado em fim de semana; jogo realizado às 21 horas e chuva (medida em milímetros). Os resultados indicaram que a demanda por jogos de futebol é inelástica em relação ao preço, assim como Madalozzo e Villar (2009). Bem como jogos no fim de semana apresentam maior demanda, jogos em dias chuvosos e depois das 21 horas tem impacto negativo na demanda.

Por fim, tem-se o trabalho de Lima Benevides et al. (2017) que objetivou encontrar os determinantes da demanda por ingresso de partidas de futebol. Para tal, o autor aplicou um modelo econométrico onde o público pagante medido em o número de ingressos vendidos foi considerado como proxy da demanda (variável explicada), enquanto as variáveis explicativas foram divididas em fatores econômicos, qualidade esperada da partida, incerteza dos resultados e fatores estruturais. As variáveis utilizadas para mensurar o aspecto econômico da demanda foram o preço médio dos ingressos, dado pela razáo entre a receita bruta e o público pagante e a renda média das famílias na cidade em que se realiza a partida.

Os fatores estruturais como tamanho da torcida, o dia da partida e se o estádio utilizado foi construído para a Copa do mundo de 2014 foram todos estatisticamente significativos ao nível de 5\% e tiveram impacto positivo sobre a demanda. Os jogos disputados nos novos estádios apresentaram um impacto de $55.85 \%$, em média, sobre a demanda. Lima Benevides et al. (2017) atribuem esse fenômeno ao fator curiosidade, que tende a ser passageiro, como pôde ser observado na Inglaterra nos anos 1990.

Enquanto partidas disputadas aos fins de semana à tarde causaram um aumento médio de cerca de 20\%. Por fim, Lima Benevides et al. (2017) concluíram que a demanda por futebol é não-linear e não-homogênea, além de ser influenciada por fatores econômicos e não-econômicos, principalmente os estruturais e esportivos. 


\section{Determinaçáo de preço a partir da Teoria do Custo Total de Hall e Hitch}

As inconsistências da teoria neoclássica impedem que se analise e se determine o par preço-quantidade produzida na maioria dos mercados sob a ótica da concorrência perfeita. Todas estas contradições são observadas de maneira simultânea, sendo mais coerente uma análise voltada para o extremo oposto, ou seja, uma análise voltada ao monopólio (Sraffa, 1926).

$\mathrm{Na}$ abordagem convencional, se estabelecem modelos de concorrência perfeita e monopolísticas com o intuito apenas de ilustrar casos extremos nos quais, supostamente, náo se verificam na realidade, servindo apenas como referência para casos similares a essas condiçóes, onde setores com muitos produtores poderiam ser caracterizados como de concorrência perfeita, por exemplo, e as imperfeiçôes encontradas são apenas de natureza friccional, não constituindo uma força suficiente que alterasse os resultados previstos pela teoria (Sraffa, 1926).

No entanto, estas imperfeições não são meramente friccionais, são "forças ativas que produzem efeitos permanentes e [...] cumulativos [...] são quase sempre dotados de estabilidade [...] para que se tornem objeto de análise com base em hipóteses estáticas" (Sraffa, 1926: 10). O autor afirma que "um pequeno desvio dessas (condiçốes de concorrência) é suficiente para fazer com que a forma como o equilíbrio é atingido tornese extremamente similar àquela forma peculiar ao monopólio" (Sraffa, 1926: 10).

É neste contexto onde se necessita de uma teoria de determinação de preços mais próxima da realidade, que o estudo de Hall e Hitch (1939) busca por meio da aplicação de questionários a algumas empresas selecionadas de acordo com seu porte, área de atuação e consideradas bem administradas, ou administradas racionalmente, entender como é a formação de seus preços. Ao todo, Hall e Hitch (1939) entrevistaram 38 empresas: 33 industriais, três varejistas e duas firmas de construção (De Oliveira Lima, 1985).

As principais conclusóes do estudo de Hall e Hitch (1939) foram: i) As firmas não agem como prevê a teoria neoclássica, ou seja, de forma atomística; ii) As firmas determinam os preços por meio da adiçáo de um mark-up sobre os custos de produção; iii) As firmas produzem enquanto o mercado é capaz de consumir e iv) Os preços tendem a se manterem fixos. Assim, pode-se dizer que o principal resultado do estudo de Hall e Hitch (1939) é a proposta de determinação de preço, tal como se apresenta na equação (1). 


$$
P=V+q^{\prime} V+q^{\prime \prime} V
$$

$P$ é o preço unitário, $V$ o custo direto, $q^{\prime}$ uma margem para cobrir os custos variáveis e $q^{\prime \prime}$ para cobrir uma margem convencional de lucro. Entâo, pode-se escrever, de acordo com Sylos-Labini (1956), que:

$$
P=V+Q V
$$

$V$ é o custo direto e $Q=q^{\prime}+q^{\prime \prime}$. Logo, tem-se que as empresas não maximizam seus lucros por meio do encontro entre as curvas de receita e custo marginal, das quais as firmas sequer têm acesso e julgam ser adequado que os preços cubram apenas os custos médios de produção de forma a gerarem lucro (De Oliveira Lima, 1985).

Dessa forma, pode-se compreender que a relação entre os Clubes de Futebol analisados e seus torcedores é de consumidores para com fornecedores, numa estrutura de mercado que reflete de maneira muito precisa o oligopólio diferenciado, termo originalmente formulado por Sylos-Labini (1956) com inspiração em Kaldor (1935) e Sraffa (1926).

Esta estrutura de mercado consiste em "muitas pequenas empresas aparentemente em concorrência entre si, mas que na realidade estão dotadas de poderes de mercado bem definidos" (Sylos-Labini, 1956: 56 como citado em Gonçalves da Silva, 2010: 125). Gonçalves da Silva também destaca "[que] uma certa diferenciação dos produtos é relevante, de modo que cada empresa está em concorrência direta, somente com alguns rivais mais próximos" (Gonçalves da Silva, 2010: 125).

Este mercado leva ao extremo a diferenciação de produto pois é improvável que torcedores deixem de comprar ingressos para jogos do seu clube de preferência em razão do preço elevado, para adquirir ingressos de partidas de outros clubes, ainda que estes tenham menores preços, ou apresentem maior qualidade do jogo em si ou estádio mais confortável. Não há, portando, um substituto perfeito, restando apenas os jogos transmitidos em TV Aberta, fechada ou pay-per-view como opção, que podem ser considerados os rivais mais próximos.

Com isso, pode-se entender que cada torcida é uma fatia específica de mercado dos clubes, onde estes podem definir os preços dos ingressos considerando os custos operacionais e definindo um mark-up, ${ }^{3}$ ou seja,

\footnotetext{
${ }^{3}$ Mark-up é uma ferramenta administrativa utilizada por muitos empresários como método para definir o preço de venda de uma mercadoria ou serviço prestado. O Manual de Economia da USP define mark-up como "a margem da receita de vendas (faturamento) sobre os custos diretos de produçâa”. Esse modelo surgiu após estudos empíricos estruturados a partir de 1930, que mostraram, segundo Vasconcellos (2002), "que as grandes empresas determinam o preço de seu produto a partir
} 
uma margem de lucro que seja conveniente e compatível com as pretensóes, sejam financeiras ou esportivas, dos ofertantes. A demanda, portanto, pode afetar a amplitude deste mark-up, tendo em vista que os estádios possuem um número limitado de assentos, não sendo possível aumentar a quantidade ofertada da maneira como é feita no setor industrial, ao menos não no curto-prazo. Assim, fatores como a importância, dia ou circunstâncias exclusivamente esportivas podem influenciar o preço dos ingressos.

\section{Metodologia}

\subsection{Descriçâo das variáveis e fonte de dados}

Para mensurar a relação entre os determinantes e os preços dos ingressos para jogos de futebol do Campeonato Brasileiro da Série A, foram utilizados dados de todos os jogos de 12 clubes, a saber: Botafogo, Flamengo, Fluminense, Vasco, Corinthians, São Paulo, Palmeiras, Santos, Cruzeiro, Atlético Mineiro, Internacional e Grêmio na condição de mandante; isto é, cuja a renda da partida e a operação do estádio são responsabilidade do clube.

Ressalta-se que embora o Campeonato Brasileiro da Série A seja disputado por 20 clubes, optou-se na presente pesquisa por manter apenas os 12 clubes citados acima que durante o período de análise (2012 a 2018) se mantiveram na série A. Essa questáo é importante do ponto de vista metodológico, visto que o modelo econométrico proposto na presente pesquisa, qual seja, o de dados em painel balanceado, pressupóem que se utilize as mesmas unidades (times de futebol) para o mesmo período de tempo. Cabe destacar que, obviamente, os resultados obtidos refletem tal estrutura de dados. Logo, para os 12 clubes que compuseram a amostra, coletaram-se as seguintes variáveis:

a) Preço Médio do Ingresso (Pm): É o preço médio no qual o ingresso foi comercializado.

b) Custo individual (Ci): As partidas de futebol apresentam diversos custos que podem ser condensados como custos operacionais. $\mathrm{O}$ custo individual é calculado pelos custos operacionais divididos pelo público pagante.

c) Dia (D): As partidas do Campeonato Brasileiro podem ser realizadas em fins de semana (sábado e domingo) ou nos dias úteis. Toma-se, portanto, que as partidas nos fins de semana possuem

de seus próprios custos, sem ater-se ao comportamento da demanda, já que eles conhecem menos da demanda do que seus custos" (Vasconcellos, 2002: 171). 
maior demanda e, assim, podem ter um impacto maior sobre o preço. Logo, construiu-se uma variável qualitativa, tipo 0 , jogo no meio de semana ou 1, jogo no fim de semana, para captar tal efeito.

d) Estádio (E): Variável que diz respeito ao tipo de estádio em que se realizou a partida. Variável qualitativa tipo 0 , estádio antigo, ou 1, estádio construído, ou reformado, recentemente, que possui características de um estádio moderno, apontadas por Holzmeister Oswaldo Cruz (2005) e Alvito (2006).

e) Desempenho (Des): Variável que busca medir o impacto do desempenho esportivo dos clubes sobre os preços. Calculado de acordo com o aproveitamento nas ediçôes do campeonato Brasileiro da Série A que compóe a amostra, considerando 2012 a 2018, por meio da quantidade de pontos conquistados.

f) Importância (Impi): Variável qualitativa que busca medir o impacto da importância da partida específica, sendo 0 para partidas comuns e 1 para partidas consideradas importantes ou decisivas (aquelas que podem definir vagas em outras competiçóes nacionais e internacionais, por exemplo).

g) Clássico (CS): É esperado que os clássicos, isto é, partidas em que ambos os times são da mesma cidade ou estado, impactem positivamente na demanda gerando um aumento positivo no preço. Portanto é uma variável qualitativa tipo 0 , quando não for clássico e 1 quando for clássico.

Salienta-se que para obter dados como a receita bruta, custo, preço médio e público dos clubes de Minas Gerais, Rio de Janeiro, Rio Grande do Sul e São Paulo, recorreu-se ao website:srgoool.com.br. Nesta ferramenta da internet podem ser encontrados os dados necessários de todos os jogos do campeonato Brasileiro ao longo do tempo. Para este artigo o período considerado foi de 2012 a 2018.

\subsection{O modelo econométrico para mensurar os determinantes dos preços dos ingressos}

Para a estimação da relação entre determinantes e preços dos ingressos de futebol do Campeonato Brasileiro da Série A, considerou-se um período de sete anos; portanto $\mathrm{t}=7$ e o número de rodadas foi de 19 por clube. Logo, o número de unidades foi de 12 vezes 19, cujo valor é de 228 e com isso o total de observaçóes no painel foi de 1,596. Assim, o modelo proposto neste artigo está representado na equação 3 e está estruturado para estimar variáveis organizadas em painel, modelo este que está minuciosamente apresentado, por exemplo, em Baltagi (2013). 


$$
\begin{gathered}
\text { Pmit }=\beta 0+\beta 1 C i i t+\beta 2 \text { Dit }+\beta 3 \text { Eit }+\beta 4 \text { Desit }+ \\
\beta 5 \text { Impiit }+\beta 6 C \text { Sit }+\beta 7 \text { odbit nit }
\end{gathered}
$$

Vale destacar que as variáveis $D$, Des, I e CS fazem parte do Mark- $U_{p}$ sobre os custos de produção, que neste artigo denominou-se de custos operacionais, conforme diz a teoria do custo total de Hall e Hitch (1939). $\mathrm{E}$ a variável $\mathrm{E}$ pode elevar o preço tanto pelo aumento de custos, quanto pelo o aumento da demanda como destacam Lima Benevides et al. (2017).

\section{Resultados e discussáo}

Nesta seção são apresentados e discutidos os resultados obtidos por meio da estimação da equação 3. Inicialmente, foram apresentadas, na tabela 1 , as estatísticas descritivas das variáveis observadas.

\section{Tabela 1}

Estatísticas descritivas das variáveis utilizadas para estimar os impactos dos determinantes dos preços dos ingressos de futebol no Campeonato Brasileiro no período de 2012 a 2018

\begin{tabular}{lccccc}
\hline \multicolumn{1}{c}{ Variável } & Observaçöes & Média & Desvio-padräo & Minimo & Máximo \\
\hline Pm & 1596 & 32.90 & 15.29 & 4.01 & 136.78 \\
$C i$ & 1596 & 21.51 & 13.64 & 2.99 & 131.99 \\
Dia & 1596 & 0.68 & 0.47 & 0.00 & 1.00 \\
Impi & 1596 & 0.25 & 0.43 & 0.00 & 1.00 \\
Des & 1596 & 0.53 & 0.15 & 0.00 & 1.00 \\
$C S$ & 1596 & 0.11 & 0.31 & 0.00 & 1.00 \\
Odb & 1596 & 0.03 & 0.17 & 0.00 & 1.00 \\
$E$ & 1596 & 0.52 & 0.50 & 0.00 & 1.00 \\
\hline
\end{tabular}

Fonte: elaboração própria a partir dos resultados da pesquisa.

Como se pode observar pela tabela 1 , a variável dependente, preço médio dos ingressos $(P m)$, obtida por meio da divisão da renda bruta pelo público pagante, foi de $\mathrm{R} \$ 32.90$, em média. O custo individual $(C i)$ que se refere ao custo total divido pelo público pagante, foi de $\mathrm{R} \$ 21.50$ em média.

O desempenho dos clubes da amostra foi em média de 53.1\%, que indica que, na maioria dos anos, estes se aproximaram e alguns até garan- 
tiam vaga na competição CONMEBOL Copa Libertadores da América (Libertadores). O bom desempenho médio pode ser explicado pelo fato de os clubes escolhidos para fazer parte da amostra serem os clubes mais populares e de maior receita do Brasil, o que se traduz em um melhor desempenho esportivo devido à possibilidade que os mesmos têm de maior investimento comparado aos demais.

Devido à presença de uma dimensão temporal nos dados da amostra, se faz necessário a aplicação do teste de raiz unitária para verificar a propriedade de estacionariedade da série de dados quantitativas, a saber: as variáveis $P m, C i$ e Des. $E$, dado que também há o componente de corte transversal (i= igual a times), os dados então estão estruturados em painel e, portanto, foi aplicado o teste Levin-Lin-Chu (LLC), cuja hipótese nula é de que o painel possui raiz unitária. Os resultados estão apresentados na tabela 2.

\section{Tabela 2}

\section{Teste de Raiz Unitária de Levin-Lin-Chu para as variáveis preço médio dos ingressos $(\mathrm{Pm})$, custo individual $(\mathrm{C} i)$ e desempenho (Des)}

\begin{tabular}{ccc}
\hline & Teste t ajustado & p-valor \\
\hline Pm & -11.021 & 0.000 \\
$C i$ & -9.532 & 0.000 \\
Des & -8.168 & 0.000 \\
\hline
\end{tabular}

Fonte: elaboração própria a partir dos resultados da pesquisa.

Conforme análise dos resultados da tabela 2 , nota-se que todos os $\mathrm{p}$ valores foram menores do que $10 \%$, isto implica em afirmar que a hipótese nula do teste LLC foi rejeitada; logo, todos os painéis são estacionários. Com isso, pôde-se prosseguir com as etapas da estimação do modelo econométrico.

Quanto à escolha do melhor método de estimação da equação 3, aplicaram-se o teste de Chow, cuja a hipótese nula é de que o modelo de Mínimos Quadrados Ordinários (MQO) é preferível ao de Efeitos Fixos (EF); teste de Breusch-Pagan, em que a hipótese nula é de MQO é preferível ao modelo de Efeito Aleatório (EA), e o teste de Hausman, que tem a hipótese nula de o modelo de EA é preferível ao EF.

Conforme a tabela 3, observa-se presença de heterocedasticidade detectada por meio do teste de White. Quanto à autocorrelação, o resultado do teste de Wooldrigde indicou para não rejeição da hipótese nula de ausência de autocorrelação para um nível de significância de 1\%. Então, 


\section{Tabela 3}

\section{Coeficientes estimados por meio do método de Efeitos Aleatórios (EA) com erros padráo-robustos}

\begin{tabular}{|c|c|c|c|c|}
\hline & Coeficientes & Erro-padrão & Estatistica $Z$ & $P>|z|$ \\
\hline Constante & 8.747 & 3.057 & 2.860 & 0.000 \\
\hline$C i$ & 0.393 & 0.097 & 4.050 & 0.000 \\
\hline Dia & 2.296 & 0.495 & 4.630 & 0.000 \\
\hline E & 12.564 & 3.518 & 3.570 & 0.000 \\
\hline Des & 13.959 & 4.078 & 3.420 & 0.001 \\
\hline Impi & -2.531 & 0.780 & -3.240 & 0.001 \\
\hline$C S$ & 6.740 & 1.407 & 4.790 & 0.000 \\
\hline$O d b$ & 2.431 & 2.272 & 1.070 & 0.285 \\
\hline$R^{2}$ & 0.2253 & & & \\
\hline \multicolumn{2}{|c|}{ Teste de White $\left(\chi^{2}\right)$} & \multicolumn{2}{|c|}{1261.980} & (p-valor $=0.000)$ \\
\hline \multicolumn{2}{|c|}{ Teste de autocorrelaçấo } & \multicolumn{2}{|c|}{7.291} & (pvalor $=0.021)$ \\
\hline \multicolumn{2}{|c|}{ Teste de Chow } & \multicolumn{2}{|c|}{79.520} & (pvalor $=0.000)$ \\
\hline \multicolumn{2}{|c|}{ Teste LM } & \multicolumn{2}{|c|}{$10,916.800$} & (pvalor $=0.000)$ \\
\hline \multicolumn{2}{|c|}{ Teste Hausman } & \multicolumn{2}{|c|}{7.720} & (pvalor $=0.358)$ \\
\hline
\end{tabular}

Fonte: elaboraçáo própria a partir dos resultados da pesquisa.

como o modelo não atendeu ao pressuposto de homocedasticidade, foi necessário a correção, que foi realizada pelo procedimento de obtenção de erros-padrão robustos. ${ }^{4}$

De acordo com os resultados apresentados na tabela 3, pode-se afirmar que os sinais dos coeficientes estimados estáo de acordo com o que aponta a revisão de literatura e a teoria apontada neste artigo, exceto para as variáveis Impi que busca captar o aumento no preço dos ingressos conforme a importância do jogo em questão, sendo considerados jogos importantes os últimos cinco jogos do time i como mandante em cada ano t e a variável Odb, na qual acreditava-se que o acordo entre o Fluminense e a Odebrecht possibilitaria uma redução dos preços dos ingressos.

Ainda conforme análise da tabela 3, a variável dummy Impi apresentou impacto negativo no preço médio nos ingressos de cerca de $\mathrm{R} \$ 2.53$, ao contrário do que se esperava. Segundo Bruscato Bortoluzzo et al. (2017),

${ }^{4}$ No stata 12, basta usar o comando vce robust que permite obter estimativas consistentes com um estimador diferente da matriz de variância-covariância dos estimadores dos parâmetros (VCE) que leve em conta os erros não i.i.d. Esta é a chamada abordagem robusta. $\mathrm{O}$ significado do termo robusto vem do fato de que nesta abordagem não há nenhuma restrição ao comportamento dos erros do modelo estimado. 
à medida que o campeonato avança, há um aumento da demanda pelas partidas de futebol; porém, este aumento não é repassado ao preço por meio do mark-up, o que pode ser explicado por fatores esportivos como o modelo de disputa popularmente conhecido como pontos corridos, implantado ao campeonato Brasileiro a partir de 2003, como também pela necessidade de mais público no estádio ao fim do campeonato com intenção de melhorar o desempenho da equipe por meio do aumento do incentivo da torcida.

Também se destaca que tal fato pode ocorrer, especialmente, em casos de clubes ameaçados de rebaixamento à série $\mathrm{B}$, aplicado aos quatro últimos colocados ao fim de 38 rodadas. Um exemplo é o caso do time Internacional, que em 2016, onde nas últimas cinco rodadas o preço médio do ingresso foi de $\mathrm{R} \$ 15.81$ em contraste aos $\mathrm{R} \$ 31.92$ das primeiras cinco rodadas e também em casos de clubes que buscam vaga na Copa Libertadores, como o Sáo Paulo que fixou preços a partir de $\mathrm{R} \$ 5.00$ para um jogo valido pela $37^{\circ}$ rodada contra o Internacional para o campeonato Brasileiro de 2019; ou ainda pelo fato de muitos clubes chegarem nas últimas rodadas com poucas ou nenhuma ambição na competiçáo. Assim, é comum que ocorram promoçôes que acabam por diminuir o preço dos ingressos.

No que se refere à variável Odb, que não foi estatisticamente significativa, ressalta-se que, embora no ano de 2016 já não houvesse mais o acordo citado, o preço médio dos ingressos para o Fluminense sofreu pouca oscilação, o que acarretou em prejuízos recorrentes, e isso pode explicar o p-valor de 0.231 encontrado para a variável. No gráfico 1 ,

\section{Gráfico 1}

\section{Lucro do Fluminense ao longo dos jogos (rodadas) como mandante} no Campeonato Brasileiro da Série A de 2013 a 2018

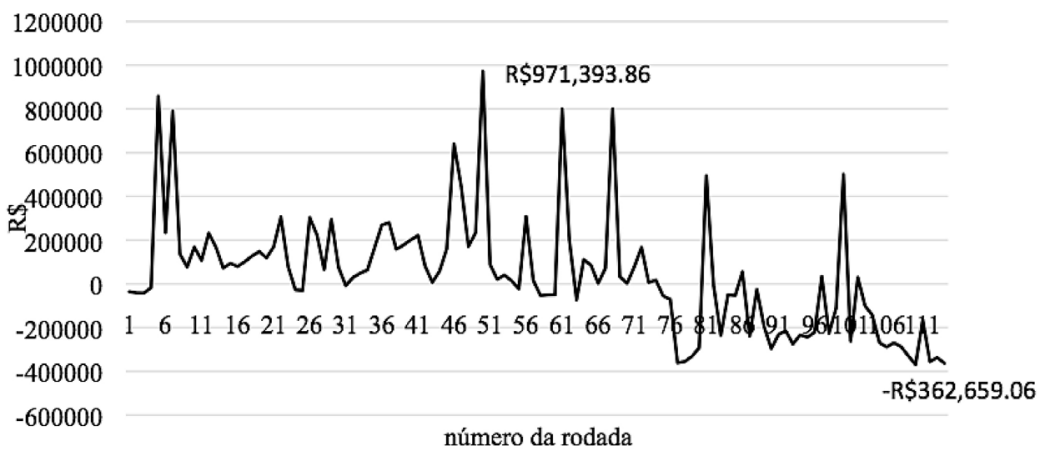

Fonte: elaboraçáo própria a partir dos dados utilizados na pesquisa. 
apresenta-se o comportamento do lucro do Fluminense enquanto mandante ao longo do período analisado e que pode corroborar o resultado encontrado para a variável Odb.

De acordo com a análise do gráfico 1, observa-se que o jogo de maior lucro foi um clássico contra o Flamengo pela $23^{\circ}$ rodada do campeonato Brasileiro de 2015, disputado no Maracaná, assim como a maioria dos picos (positivos), exemplificando o impacto na demanda por jogos, e consequentemente no mark-up, causados por clássicos regionais. A exceção se dá no jogo contra o Grêmio, também pelo campeonato Brasileiro de 2015, na estreia do Ronaldinho Gaúcho pelo Fluminense, jogador de grande prestígio mundial e revelado pelo time adversário (Grêmio).

Esse contexto foi um fator de aumento do mark-up para esse jogo em específico, auferindo-se um lucro de $\mathrm{R} \$ 639,395.41$. Assim, pode-se dizer que a diminuição dos lucros a partir de 2016 se deu pelos fatores citados no parágrafo acima e que não teria relação forte com o desempenho da equipe.

Quanto às estimativas dos demais coeficientes, observou-se também conforme análise da tabela 3, que os mesmos estáo de acordo com o referencial teórico no qual se baseou este trabalho. Em relação ao intercepto estimado, este foi de $\mathrm{R} \$ 8.75$, que pode ser interpretado como custos fixos médios do jogo; ou seja, custo fixo dividido pelo público pagante, independente das condiçóes esportivas em questão, bem como o custo variável.

Verificou-se também que o aumento do custo individual, ou custo unitário, representado pela variável Ci pode ter levado a um aumento no preço dos ingressos. Assim, para cada $\mathrm{R} \$ 1.00$ de aumento no custo unitário, implicou em um aumento de $\mathrm{R} \$ 0.39$ no preço médio dos ingressos, em média, tudo mais mantido constante. Embora o sinal esteja de acordo com os princípios da teoria, pode-se dizer que o valor adicional de $\mathrm{R} \$ 0.39$ é baixo tendo como parâmetro a variação unitária $(\mathrm{R} \$ 1.00)$ e não repóem totalmente o aumento do custo. Isto significa afirmar que não há como um clube repassar totalmente os custos aos torcedores que vão ao estádio, o que pode causar prejuízos a depender do volume de pagantes.

No que tange à variável Dia, na qual, caso a partida fosse realizada no meio de semana receberia valor 0 (zero) e caso fosse realizada aos fins de semana, a saber, sexta-feira, sábado e domingo, receberia valor 1 (um), esta apresentou um coeficiente estimado de 2.30. Ou seja, partidas realizadas no fim de semana tem um impacto de, em média, $\mathrm{R} \$ 2.30$ a mais no preço médio dos ingressos, tudo o mais mantido constante, quando comparadas com partidas no meio de semana.

Este resultado pode decorrer do fato de que jogos em fim de semana, geralmente, têm maior demanda do que os realizados em dias em que a maior parte da população está ocupada; assim, uma maior demanda 
pode elevar a amplitude do mark-up definido pelos clubes, tudo mais mantido constante, e tal resultado condiz com os estudos de Bruscato Bortoluzzo et al. (2017) e Lima Benevides et al. (2017).

Quanto à variável Des, esta busca captar o impacto do desempenho do clube ao longo do campeonato. Para mensurar o desempenho foi usado o aproveitamento percentual dos pontos em disputa até cada rodada, por exemplo: se o clube A na rodada de número 10 tem 20 pontos, com uma vitória valendo três, um empate valendo um e uma derrota valendo 0 (zero), isso significa que de 30 pontos em disputa (10 vezes 3 ) o clube obteve $66.7 \%$ de aproveitamento, ou 20 dividido por 30 . Isto posto, constatou-se entáo que para cada ponto percentual a mais no desempenho, há um acréscimo, em média, de $\mathrm{R} \$ 0.14$ na variável $\mathrm{PM}$, com tudo mais mantido constante. Assim, pode-se interpretar que, em geral, o melhor desempenho do clube faz com que a demanda pelos jogos e, portanto, o mark-up definido pelos clubes, aumentem os preços médios do ingresso.

Em relação à variável CS, que objetivava aferir o impacto dos clássicos no preço dos ingressos; isto é, jogos entre clubes do mesmo estado, devido à maior demanda atraída pela rivalidade do jogo, foi atribuída o valor 1 (um) para os clássicos e 0 (zero) para os demais jogos. $\mathrm{O}$ resultado estimado foi de um aumento, em média, de $\mathrm{R} \$ 6.74$ para os clássicos, conforme previsto anteriormente. Resultado também em linha com os estudos empíricos de Madalozzo e Villar (2009) e Bruscato Bortoluzzo et al. (2017), que detectaram um aumento da demanda por jogos entre rivais locais.

Por fim, para a variável dummy E, que tinha por intuito detectar o impacto dos novos estádios construídos, em sua maioria, para a Copa do mundo de 2014, recebendo, assim, o valor 1 (um) para os estádios considerados modernos e 0 (zero) para estádios considerados antigos, verificou-se que o coeficiente estimado para a variável foi de 12.56. Portanto, os estádios modernos têm um impacto de $\mathrm{R} \$ 12.56$, em média, sobre o preço dos ingressos. Tal fenômeno pode ser interpretado como um aumento do custo operacional dos estádios mais novos em relação aos estádios mais antigos, devido à maior qualidade dos assentos e instalaçóes, bem como medidas de segurança adotadas devido às exigências da FIFA.

Cabe ressaltar que, segundo o estudo de Lima Benevides et al. (2017), há um aumento da demanda por jogos de futebol em estádios mais modernos, fator também relevante para o aumento do preço nesses estádios. Portanto, a hipótese de que o aumento dos custos dos estádios modernos, ou padrão FIFA, provoca aumento nos preços dos ingressos, pode ser aceita. 


\section{Conclusóes}

O presente trabalho teve como objetivo principal mensurar as relaçóes entre os determinantes dos preços dos ingressos de futebol, considerando uma mostra de 12 clubes que disputaram o Campeonato Brasileiro de Futebol da série A no período de 2012 a 2018. Os resultados se mostram de acordo com o que se discutiu na revisão de literatura e no referencial teórico. Apenas a variável Impi, que buscava mensurar o impacto das últimas cinco rodadas, que apresentou sinal contrário ao previsto.

Pode-se concluir então que a teoria do custo total de Hall e Hitch (1939) testada a partir do modelo proposto neste artigo explicaram de forma satisfatória o comportamento do preço dos ingressos de futebol no campeonato Brasileiro para o período analisado, ressaltando-se que a aplicação de qualquer teoria econômica ao futebol deve sempre buscar conciliar as especificidades esportivas que fazem parte deste contexto.

Assim, a precificação dos ingressos pode ser ajustada à demanda específica por aquela partida, levando-se em conta, por exemplo, o dia em que é realizada, o adversário, o desempenho recente, bem como os custos operacionais e ambiçóes da equipe, de forma a ter sempre no torcedor não só uma fonte de receita, mas também estabelecer uma relação de fidelidade e parceria, onde este não se sinta excluído ou tratado apenas como um mero consumidor, mas como parte importante naquele evento e no dia-a-dia do clube. Tal ação pode garantir maior fidelização, aumento do número de sócios torcedores, expansão da marca e consequentemente, aumentos de receitas e lucros.

Vale ressaltar que a forma de contabilização das receitas e despesas nos borderôs dos jogos (que é uma espécie de relatório que discrimina uma série de informaçóes relacionadas ao dinheiro gerado pelo jogo) disputados no Brasil não possuem um padrão de contabilização bem definido, e nem são expostos de forma permanente em algum endereço eletrônico, o que dificultou a coleta de dados e um maior detalhamento entre os custos e a comparação entre os desempenhos dos clubes, sendo este um dos desafios neste tipo de pesquisa.

Em tempo, destaca-se como fatores limitantes desta pesquisa o fato de que no modelo econométrico não terem sido incluídas variáveis que pudessem capturar o comportamento humano tal como o fato da irracionalidade do torcedor diante seu fascínio por um clube ou um ídolo. Mas, tal estratégia de pesquisa, se deu em virtude da dificuldade de se criar variáveis que pudessem medir esse comportamento e assim inseri-las no modelo estimado sem gerar viés nas estimativas obtidas. Logo, como sugestóes para pesquisas futuras, seria interessante buscar mensurar tais 
variáveis e verificar o impacto das mesmas no comportamento dos preços dos ingressos de futebol do Campeonato Brasileiro da Série A.

\section{Referências}

Alvito, Marcos (2006), "A parte que cabe neste latifúndio: O Futebol Brasileiro e a Globalização", Análise Social, 41 (179), Lisboa, Universidade de Lisboa, Instituto de Ciências Sociais, pp. 451474, <https://bit.ly/3lHON54>, 28 de junho de 2019.

Andrade de Melo, Victor (2010), Os sports e as cidades brasileiras: transição dos séculos XIX e XX, Rio de Janeiro, Apicuri.

Baltagi, Badi Hani (2013), Econometric Analysis of Panel Data, New Delhi, Editora Wiley.

Bruscato Bortoluzzo, Adriana; Mesquita Bortoluzzo, Mauricio; Jurandyr Machado, Sérgio; Terabavashi Melhado, Tatiana; Iarapoli Trindade, Pedro e Santos Pereira, Bruno (2017), "Ticket consumption forecast for Brazilian championship games", Revista de Administração, 52 (1), São Paulo, Universidade de São Paulo, Faculdade de Economia, Administração e Contabilidade, Departamento de Administração, pp. 70-80.

De Oliveira Lima, Luiz Antônio (1985), "Mark-up e determinação de preços no oligopólio - a microempresa em busca de realismo", Revista de Administração de Empresas, 25 (2), São Paulo, FGV (Fundação Getúlio Vargas), pp. 29-35.

Falter, Jean-Marc and Perignon, Christophe (2000), "Demand for football and intramatch winning probability: An essay on the glorious uncertainty of sports", Applied Economics, 32 (13), Oxfordshire, Taylor \& Francis, pp. 1757-1765.

García, Jaume and Rodríguez, Plácido (2002), “The determinants of football match attendance revisited: Empirical evidence from Spanish football league", Journal of Sports Economics, vol. 3, Thousand Oaks, SAGE Journal, pp. 18-38.

Gonçalves da Silva, Ana Lucia (2010), "Concorrência sob condiçôes oligopolísticas. Contribuição das análises centradas no grau de atomização/concentração dos mercados", tese de doutorado, 
Universidade Estadual de Campinas, Instituto de Economia (UNICAMP), Campinas.

Guimarães Simões, Paula (2017), "O futebol e seus ídolos: David Luiz na Copa do Mundo de 2014”, RuMoRes, 21 (11), São Paulo, MidiAto/Grupo de Estudos de Linguagem e Práticas Midiáticas, pp. 151-170.

Hall, Robert Lowe e Hitch, Charles Johnston (1939), "Price theory and economic behaviour", Oxford Economic Papers, 2 (1), Oxford, Oxford University Press, pp. 12-45.

Holzmeister Oswaldo Cruz, Antônio (2005), A Nova economia do futebol: uma análise do processo de modernização de alguns estádios brasileiros, dissertação mestrado em Antropologia Social, Universidade Federal do Rio de Janeiro, Rio de Janeiro.

Kaldor, Nicholas (1935), "Market imperfection and excess capacity", Economica, 2 (5), Londres, JSTOR, pp. 33-50.

Lima Benevides, Bruno Ítalo; dos Santos Sandra Maria e de Aquino Cabral, Augusto Cézar (2017), "A relação entre preço por jogos de futebol no Brasil”, Revista de Economia Contemporânea, 21 (2), Rio de Janeiro, Universidade Federal do Rio de Janeiro, Instituto de Economia, pp. 1-18.

Madalozzo, Regina and Beber Villar, Rodrigo (2009), "Brazilian football: what brings fans to the game?", Journal of Sports Economics, 10 (6), Thousand Oaks, SAGE Journal, pp. 639-650.

Rial Butier, Lucas e Levrini, Gabriel (2013), "Fatores que influenciam a compra de produtos têxteis oficiais por torcedores de futebol de baixa renda", PODIUM: Sport, Leisure and Tourism Review, 2 (2), São Paulo, Universidade Nove de Julho, pp. 143-172.

Sampaio, Claudio; Sordi, Jefferson e Gattermann Perin, Marcelo, (2015). "O papel do envolvimento e do orgulho nas decisóes de consumo de pacotes de preços: um estudo com ingressos de futebol no Brasil", PODIUM: Sport, Leisure and Tourism Review, 4 (3), São Paulo, Universidade Nove de Julho, pp. 113-123.

Sandoval de Vasconcellos, Marco Antônio (2002), Economia: micro e macro, São Paulo, Atlas. 
Sports Value (2018), “As finanças dos clubes brasileiros 2018”, São Paulo, Sports Value, <https://bit.ly/39KmrF4>, 28 de junho de 2019.

Sraffa, Piero (1926), "As leis dos rendimentos sob condiçōes de concorrência”, The Economic Journal, vol. 36, Londres, Estelle Cantillon Nezih, pp. 535-550. Tradução: Claudia Heller, Universidade Estadual de São Paulo, Araraquara, SP. 1991.

Sylos-Labini, Paolo (1956), Oligopoly and technical progress, Cambridge, Harvard University Press.

Varian, Hal Ronald (2006), Microeconomia: princípios básicos, Rio de Janeiro, Elsevier.

Recebido: 18 de maio de 2020. Encaminhado: 7 de novembro de 2020.

Graciela Aparecida Profeta. Doutora em Economia Aplicada pela Universidade Federal de Viçosa. Atualmente é professora da Universidade Federal Fluminense em exercício no Conselho Administrativo de Defesa Econômica (CADE), desde fevereiro de 2020. É professora do o mestrado em Propriedade Intelectual e Transferência de Tecnologia (PROFINIT). Atua nas áreas de econometria/estatística e microeconomia com ênfase em organizaçáo industrial, estudos industriais e estudos aplicados ao desenvolvimento regional. Entre suas publicaçôes mais recentes estão, como coautora: "Consumo de eletricidade e PIB: uma análise em dados em painel para o Brasil no período de 2002 a 2015", Bioenergia em Revista: Diálogos, 10 (1), Sáo Paulo, FATEP (Faculdade de Tecnologia de Piracicaba), pp. 92-110 (2020); "Mensuração do poder de mercado na exploração de rodovias no Brasil: uma análise econométrica para o período de 2002 a 2012", Economic Analysis of Law Review, 10 (3), Brasilia, UCB (Universidade Católica de Brasília), pp. 79-107 (2019); "Pluriatividade e economia criativa: um estudo de caso sobre a geração de renda no assentamento Zumbi dos Palmares-Campos dos Goytacazes, RJ", CAMPO-TERRITÓRIO: Revista de Geografia Agrária, 14 (34), Porto Alegre, Universidade Federal de Uberlândia, pp. 109-137 (2019).

Ivens Nunes Thomaz. Graduado em Ciências Econômicas pela Universidade Federal Fluminense. Tem interesse em pesquisas sobre Economia do Esporte. 
Patrícia de Melo Abrita Bastos. Doutora em Economia Aplicada pela Universidade Federal de Viçosa. Professora da Universidade Federal Fluminense. É líder do Grupo de Estudos em Economia Ambiental e Economia Ecológica. Atua principalmente nos seguintes temas: concentração de renda, pobreza, econometria. Entre suas publicaçôes mais recentes estão, como coautora: "Determinantes da pobreza no meio rural brasileiro", Revista de Estudos Sociais (UFMT), 20 (41), Cuiabá, Universidade Federal de Mato Grosso, Faculdade de Economia, pp. 4-30 (2019); "Estudo da viabilidade econômico-social de um projeto de reflorestamento da área de preservação permanente (APP) de Cataguarino", Revista de Politica Agrícola, 21 (1), Viana, Publicação SPA, pp. 22-37 (2012); "Mercado de trabalho e rendimento no meio rural brasileiro", Economia Aplicada, 14 (3), Ribeirão Preto, Faculdade de Economia, Administração e Contabilidade de Ribeirão Preto da Universidade de São Paulo, pp. 355379 (2011).

Vladimir Faria dos Santos. Doutor em Economia Aplicada pela Universidade Federal de Viçosa. Professor da Universidade Federal Fluminense. Atua na área de Economia Aplicada, com ênfase em Métodos Quantitativos em Economia. Atualmente é líder do Núcleo de Estudos em Economia Aplicada (NEEA/UFF). Entre suas publicaçóes mais recentes estão, como coautor: "Consumo de eletricidade e PIB: uma análise em dados em painel para o Brasil no período de 2002 a 2015", Bioenergia em Revista: Diálogos, 10 (1), São Paulo, FATEP (Faculdade de Tecnologia de Piracicaba), pp. 92-110 (2020); "Distribuição de renda no Brasil: uma análise de decomposição", Vértices (Campos dos Goitacazes), 21 (2), Cidade Campos dos Goytacazes, IFFluminense (Instituto Federal de Educação, Ciência e Tecnologia Fluminense), pp. 328-343 (2019); Influência dos acidentes de trânsitos em rodovias federais sobre os custos do Sistema Único de Saúde, no período 2002 a 2012. Estudo \& Debate, 26 (4), Rio Grande do Sul, Univates (Universidade do Vale do Taquari), pp. 145-162 (2019). 